\title{
The Role of High Resolution Ultrasound in the Assessment of Knee Osteoarthritis
}

\author{
SAMAR M.I. SHAABAN, M.Sc.; MARWA I. FAHMY, M.D. and TAREK W. HEMADA, M.D. \\ The Department of Radiology, Faculty of Medicine, Ain Shams University
}

\begin{abstract}
Background: Osteoarthritis (OA) is a common musculoskeletal disease with high prevalence worldwide. Knee OA is primary diagnosed using conventional radiography, however, changes of articular cartilage or menisci cannot be directly assessed using conventional radiology. Ultrasound (US) can be used to assess soft tissue degeneration directly.
\end{abstract}

Aim of Study: The aim of this study is to evaluate the efficacy of High Resolution Ultrasound (HRUS) in the assessment of structural abnormalities found in knee osteoarthritis.

Patients and Methods: The study was conducted upon 20 patients with knee OA (12F, $8 \mathrm{M}$; mean age 53 years), each subject was evaluated for the presence of medial and lateral femoral cartilage thinning, medial and lateral femoral and tibial osteophytes, medial and lateral meniscal degeneration, joint effusion and Baker's cyst using ultrasound and MRI, considering MRI as a reference standard.

Results: The overall sensitivity of the ultrasound in the detection of knee OA parameters was good $(89.3 \%)$, the overall accuracy was excellent $(90 \%)$, the overall specificity was excellent $(93.1 \%)$. The Positive Predictive Value (PPV) and the Negative Predictive Value (NPV) were 98.3 and 65.9 respectively. The $p$-value was highly significant $(<0.01)$ when comparing assessment of knee osteoarthritis parameters between ultrasound and MRI.

Conclusion: Ultrasound assessment of the knee joint is an accurate imaging method for detection of knee osteoarthritis parameters including medial and lateral femoral articular cartilage thinning, medial and lateral osteophytes, medial and lateral meniscal degeneration, joint effusion and Baker's cyst. Thus, Knee ultrasound can be used as a complementary imaging technique to radiography, especially when MRI is not available, to assess tissue-specific structural OA degeneration not detected by conventional radiographs.

Key Words: Osteoarthritis - Knee - Ultrasound-MRI.

\section{Introduction}

OSTEOARTHRITIS (OA) is a common musculoskeletal degenerative disease. Prevalence of knee

Correspondence to: Dr. Samar M.I. Shaaban, E-Mail: samarmohamed179@ hotmail.com
OA in aging populations is increasing worldwide and is associated with significant health economic consequences. OA is recently seen as a wholeorgan disorder. Besides articular cartilage degeneration, formation of osteophytes, bone erosion, meniscus atrophy, effusion and synovial inflammation are hallmarks of the disease [1].

The epidemiology of the disorder is complex and multifactorial, with genetic, biological, and biomechanical components. Joint replacement is an effective treatment for symptomatic end-stage disease, although functional outcomes can be poor and the lifespan of prostheses is limited. Consequently, the focus is shifting to disease prevention and the treatment of early osteoarthritis. This task is challenging since conventional imaging techniques can detect only quite advanced disease [2] Recommendations for the diagnosis of knee OA include three main symptoms: Knee pain, shortlived morning stiffness, and functional limitation in combination with three signs on physical examination (crepitus, restricted movement and bony enlargement) [3] .

Severity of knee OA is primarily assessed using conventional radiography especially by evaluation of Joint Space Narrowing (JSN). However, Structural alterations visible on radiographs such as bone abnormalities and JSN are known to appear only at relatively late stages of the disease. It is also known that JSN is a surrogate of both cartilage thinning and meniscal extrusion, and there are no means to directly evaluate cartilage and meniscus morphological damage from radiographs [1]. MRI has been the most accurate modality used to evaluate the different roles of structural disorders in incident knee osteoarthritis, to compare predictability of individual features of semi quantitative 
scores for knee replacement and to formulate different disease progression models [4]. Despite its best sensitivity, MRI is expensive and sometimes not practical. For some patients MRI is difficult to be used because of the presence of a pacemaker or other absolute or relative contraindication to MRI.

Nowadays, ultrasonography is a promising technique for assessing soft tissue abnormalities such as joint effusion, synovial hypertrophy, Baker's cyst, and other structural changes including the decrease in cartilage thickness, meniscus bulging, and formation of osteophytes [5]. Advantages of ultrasound include its easy availability and multiplanar capability, as well as economic advantages. Also its ability to compress, dynamically assess structures and compare easily with the contralateral side. A great advantage of knee ultrasound is the assessment of para-articular disease. With ultrasound, the patient's point of clinical tenderness can be correlated with the underlying anatomical structures and associated pathology.

\section{Patients and Methods}

This study was a cross sectional study carried on 20 patients with knee OA $(12 \mathrm{~F}, 8 \mathrm{M}$; their age ranged from 35-75 with mean age 53 years). Patients were referred from the Outpatient Clinics of the Orthopedics and Rheumatology Departments. The study was carried out from September 2018 to July 2019 at the Radiology Department of Ain Shams University Hospitals.

Comprehensive explanations of the procedures were provided for all cases (Table 1).

Table (1): Distribution of the studied cases according to different parameters $(n=20)$.

$\begin{array}{ll}\text { Age: } & \\ \text { Range } & 35-75 \\ \text { Mean } \pm \text { SD } & 52.85 \pm 11.20 \\ \text { Gender: } & \\ \text { Female } & 12(60 \%) \\ \text { Male } & 8(40 \%) \\ \text { Side: } & \\ \text { Left } & 12(60 \%) \\ \text { Yes } & 8(40 \%)\end{array}$

\section{Inclusion criteria:}

1- Age group: Patients above 30 years age.

2- Patients clinically suspected or diagnosed as knee osteoarthritis.

\section{Exclusion criteria:}

1- Patients with history of recent significant trauma or surgery.

2- Patients with history of inflammatory arthritis or other medical conditions affecting knee joint.

Equipment: Dynamic ultrasound imaging was conducted using clinical ultrasound (LOGIQ P7) with high frequency linear transducer $(6-12 \mathrm{MHz})$. B-mode imaging settings were kept constant for each subject and focus was always set at the level of region of interest. Knee ultrasound was performed and interpreted by experienced musculoskeletal radiologist. Each patient was examined for the presence of medial and lateral femoral cartilage thinning, medial and lateral osteophytes, medial and lateral meniscal degeneration, joint effusion and popliteal cyst. With the patient lying supine and knee slightly flexed $20-30^{\circ}$, suprapatellar and parapatellar joint recesses were evaluated for joint effusion. The probe is then moved laterally and medially to evaluate the parapatellar joint recesses. The V-shaped hypoechoic hyaline cartilage covering the femoral trochlea was examined with the knee in full flexion. With the knee slightly flexed and external rotation of the hip, the Anterior Horn of Medial Meniscus (AHMM) was examined, also femur and tibia were examined for detection of the presence of osteophytes. Maintaining slight flexion of the knee, but with internal rotation of the hip, the Anterior Horn of Lateral Meniscus (AHLM) was examined and lateral femur and tibia were examined for the presence of osteophytes. With the patient prone, and the transducer in the sagittal plane, the probe was moved over the medial and lateral aspects of the posterior knee for the assessment of posterior horns of medial and lateral menisci.

The MRI study was performed in MRI Unit of Radiology Department, Ain Shams University Hospitals using super conductive MR scanner (Philips Achieva-XR 1.5 Tesla), using a standard scanning protocol. It was interpreted by an experienced musculoskeletal radiologist.

\section{Results}

Each subject was evaluated for the presence of medial and lateral femoral cartilage thinning, medial and lateral femoral and tibial osteophytes, medial and lateral meniscal degeneration, joint effusion and Baker's cyst using ultrasound and MRI. Figs. $(1,2)$. 


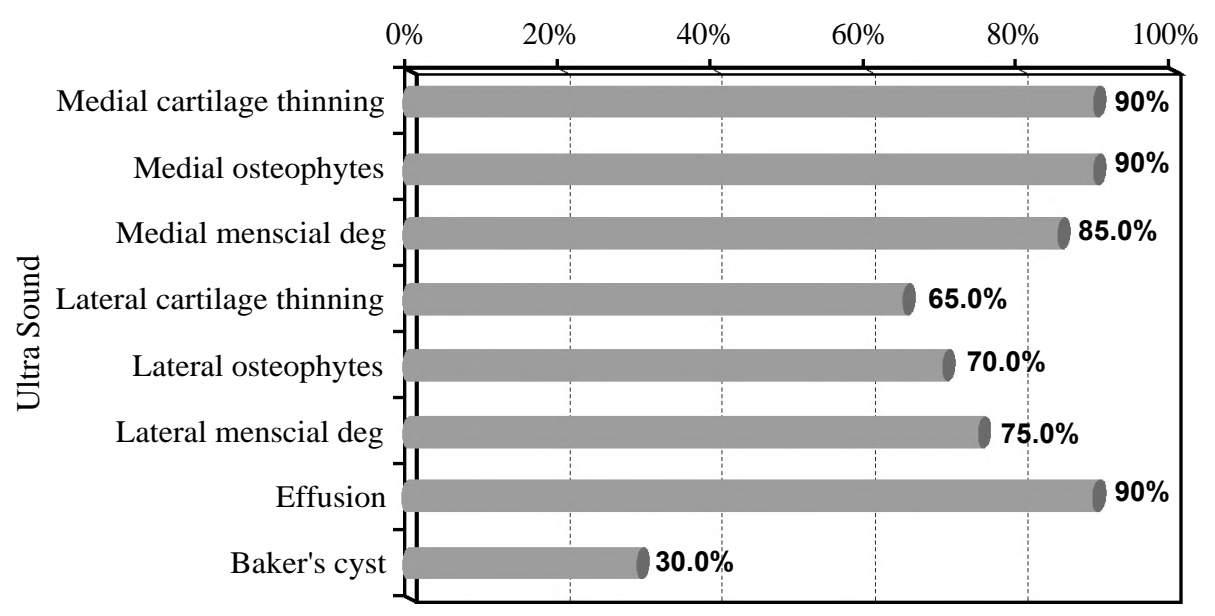

Fig. (1): US findings in all subjects.

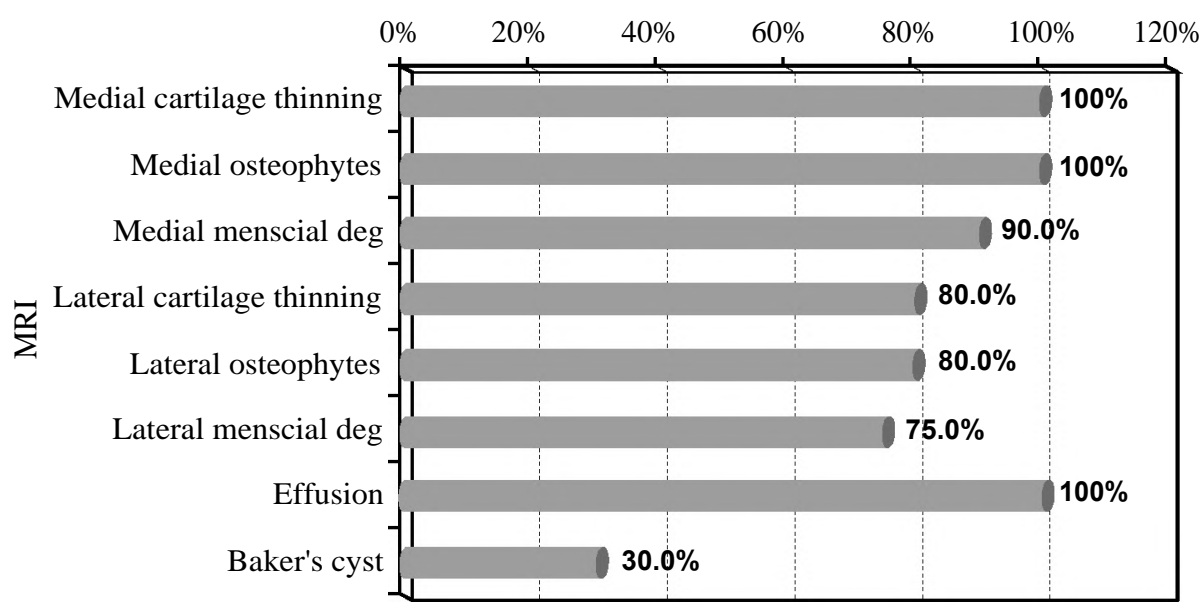

Fig. (2): MRI findings in all subjects.

The sensitivity, specificity, accuracy, Positive Predictive Value (PPV) and Negative Predictive Value (NPV) for each parameter were calculated. A sensitivity lower than $70 \%$ was considered as indicator of poor performance, from $70 \%$ to $80 \%$ as fair, from $80 \%$ to $90 \%$ as good and greater than or equal to $90 \%$ as excellent performance. The $p$ value for each parameter was calculated using chisquare test, $p$-value $<0.01$ was considered highly significant, $p$-value $<0.05$ was considered significant, while $p$-value $>0.05$ was considered nonsignificant.

The sensitivity of ultrasound was excellent in the detection of medial cartilage thinning (90\%), medial osteophytes (90\%), medial and lateral meniscal degeneration $(94.4 \%$ and $93.3 \%$ ), joint effusion (90\%) and Baker's cyst (100\%), it was good in the detection of lateral osteophytes $(87.5 \%)$, while it was fair in the detection of lateral cartilage thinning (75\%).

The accuracy of ultrasound was excellent in the detection of medial cartilage thinning (90\%), medial and lateral osteophytes (90\% for both), medial and lateral meniscal degeneration $(95 \%$ and $90 \%$ ), joint effusion (90\%) and Baker's cyst $(100 \%)$, while it was fair in the detection of lateral cartilage thinning $(75 \%)$.

The specificity of ultrasound detection of medial meniscal degeneration, lateral osteophytes and Baker's cyst was $100 \%$, while it was $80 \%$ and $75 \%$ for lateral meniscal degeneration and lateral cartilage thinning respectively.

$p$-values for medial and lateral meniscal degeneration, lateral osteophytes and Baker's cyst were all $<0.01$ (highly significant), while only the $p$ value for lateral femoral cartilage thinning was non-significant $(p$-value $=0.06)$.

The specificity, NPV and the $p$-value couldn't be calculated for medial cartilage thinning, medial osteophytes and joint effusion as they were positive in all subjects, so we had no true negatives nor false positives in our results. 
The overall sensitivity of the ultrasound in knee OA was $89.3 \%$, the overall specificity was $93.1 \%$, the overall accuracy was $90 \%$, while the overall
PPV and NPV were 98.3 and 65.9 respectively and the $p$-value was $<0.01$ (highly significant) (Table 2).

Table (2): The diagnostic performance values of ultrasound detection of knee OA parameters in reference to corresponding magnetic resonance imaging.

\begin{tabular}{lcccccc}
\hline Parameters & Sensitivity & Specificity & Accuracy & PPV & NPV & $p$-value \\
\hline Medial cartilage thinning & 90.0 & - & 90.0 & 100.0 & - & - \\
Medial osteophytes & 90.0 & & 90.0 & 100.0 & & \\
Medial menscial deg & 94.4 & 100.0 & 95.0 & 100.0 & 66.7 & $<0.01$ \\
Lateral cartilage thinning & 75 & 75 & 75 & 92.3 & 42.9 & 0.06 \\
Lateral osteophytes & 87.5 & 100.0 & 90.0 & 100.0 & 66.7 & $<0.01$ \\
Lateral menscial deg & 93.3 & 80 & 90 & 93.3 & 80.0 & $<0.01$ \\
Effusion & 90.0 & & 90.0 & 100.0 & & \\
Baker's cyst & 100.0 & 100.0 & 100.0 & 100.0 & 100.0 & $<0.01$ \\
\hline Total & 89.3 & 93.1 & 90 & 98.3 & 65.9 & $<0.01$ \\
\hline
\end{tabular}

PPV: Positive Predictive Value. NPV: Negative Predictive Value

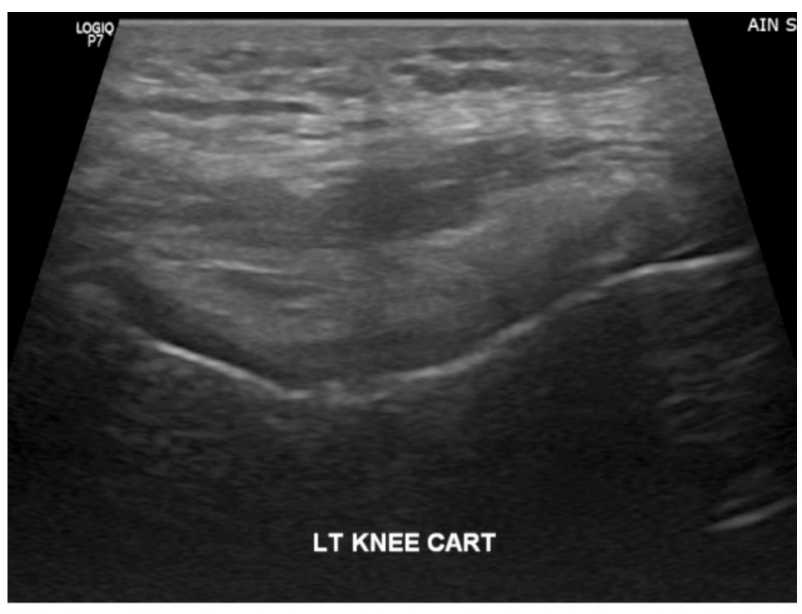

(A)

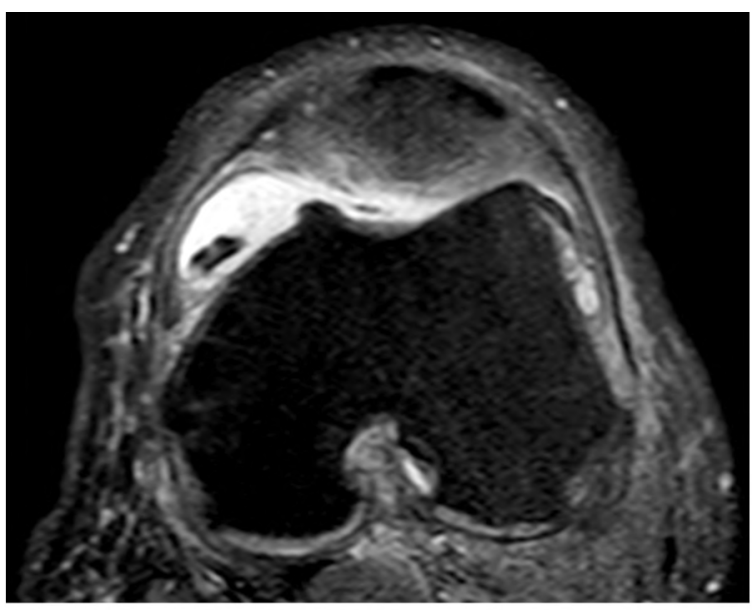

(B)

Fig. (3): 54 years old male complains of increasing left knee pain for the last 3 months. US image (A) and corresponding axial PD MRI image (B) showing severe femoral cartilage thinning.

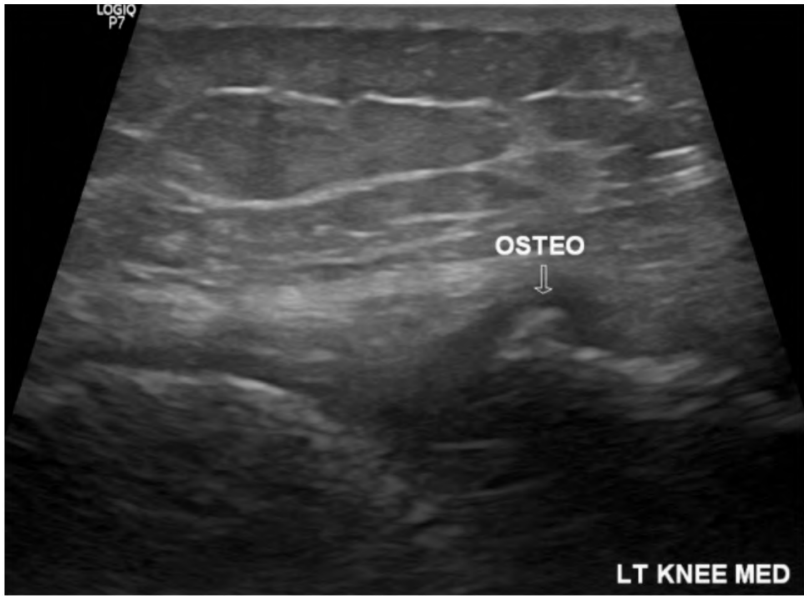

(A)

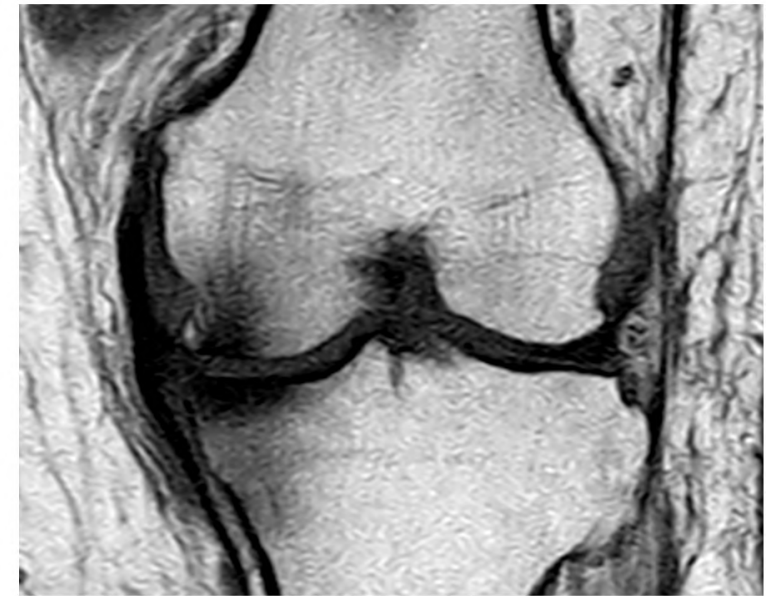

(B)

Fig. (4): 62 years old male complains of left knee pain for long duration. US image (A) and corresponding coronal T1 MRI image (B) showing osteophytes. 


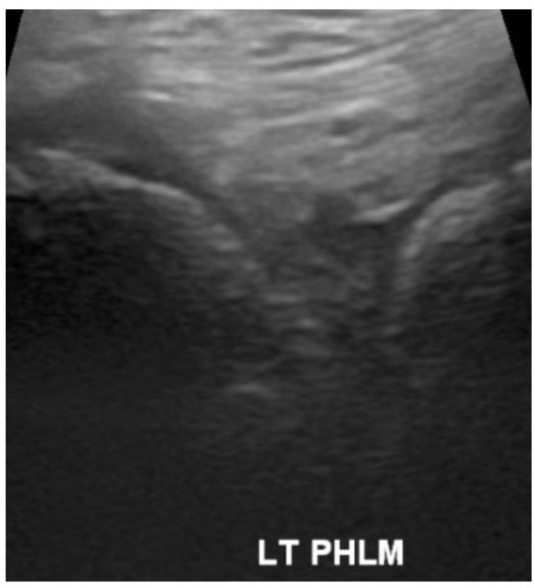

(A)

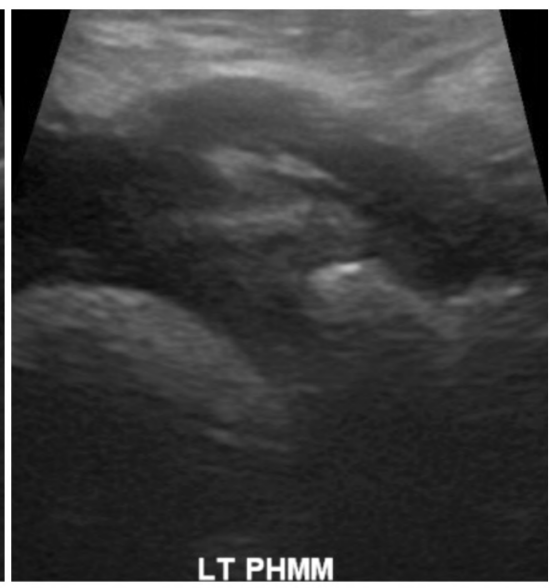

(B)

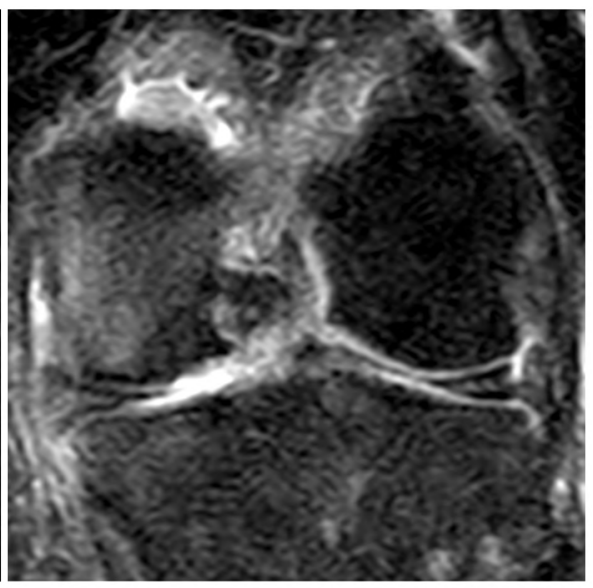

(C)

Fig. (5): US images (A) and (B) with corresponding coronal PD MRI image (C) showing degenerated both PHLM and PHMM with PHMM root tear appeared only in the MRI.

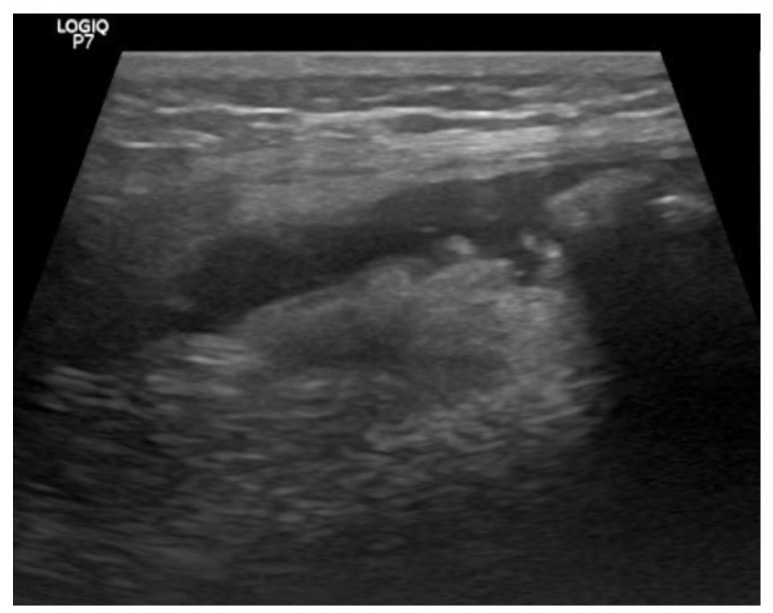

(A)

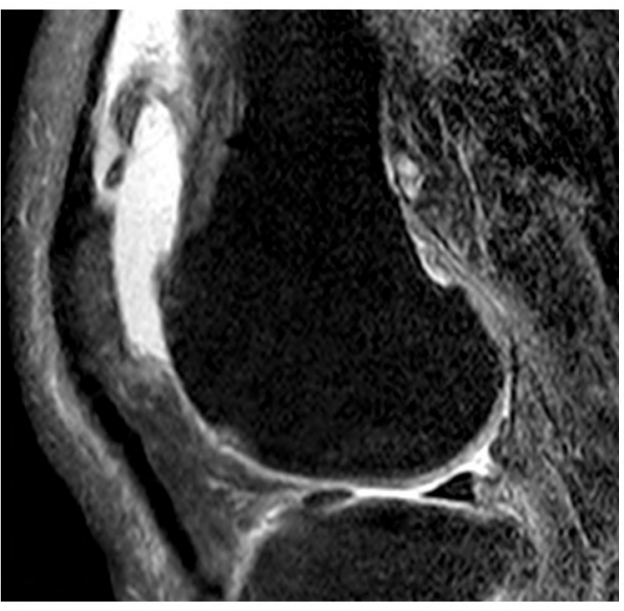

(B)

Fig. (6): US image (A) and corresponding sagittal PD MRI image (B) showing joint effusion.

\section{Discussion}

Recently, high-resolution ultrasound has become a promising tool in knee osteoarthritis study. Evidence on ultrasound validity in comparison to traditional knee osteoarthritis imaging modalities is increasing [6]. Advantages of ultrasound include its easy availability and multiplanar capability, as well as economic advantages. Also its ability to compress, dynamically assess structures and compare easily with the contralateral side. A great advantage of knee ultrasound is the assessment of para-articular disease. With ultrasound, the patient's point of clinical tenderness can be correlated with the underlying anatomical structures and associated pathology [7]. In addition, for some patients sonography may be the test of choice, because of the presence of a pacemaker or other absolute or relative contraindication to MRI.
Our study demonstrated that ultrasound can be reliably used in the assessment of knee OA parameters including femoral articular cartilage thinning, osteophytes, medial and lateral meniscal degeneration, joint effusion and popliteal cyst.

In our study, the overall sensitivity of the ultrasound in the assessment of knee OA parameters was good (89.3\%), the overall accuracy was excellent $(90 \%)$ and the overall specificity was $93.1 \%$, with a highly significant $p$-value $(<0.01)$.

In line with our study, a recent study by Sadeghian and Niya, 2018, demonstrated that for the knee joint the overall agreement of US findings with MRI was $89 \%$. The overall sensitivity for US of the knee joint was $95.59 \%$, the overall specificity $81.88 \%$ in the detection of knee osteoarthritis and rheumatoid arthritis parameters [6]. 
Our findings are also supported by a study done by Koski et al., 2016 and another study by Podlipská et al., 2016, the two studies reported that ultrasound is more sensitive than radiography in the determination of osteophytes, cartilage thinning and meniscal extrusion in the medial and lateral compartments of the knee joint $[\mathbf{1 , 8}]$.

Another recent study conducted upon 80 patients to assess the reproducibility of ultrasound findings of knee osteoarthritis published by Abdel Razek A.A. and El-Basyouni S.R., 2016 showed an excellent inter-observer agreement for the detection of articular cartilage thinning, osteophytes, joint effusion, popliteal cyst, synovial thickening and meniscal protrusion [8]

Nishitani et al., 2014, also reported that ultrasound $(10 \mathrm{MHz})$ can detect macroscopically undetectable changes in OA reflecting histological and biochemical degeneration in both rabbit and human OA samples, respectively [9]

However our study showed good to excellent allover sensitivity, accuracy and specificity for ultrasound in the detection of different parameters in knee OA, there were some limitations that need mentioning. First, our study had a relatively small number of patients. Secondly, all patients included in our study was diagnosed as knee OA, so some parameters as medial cartilage thinning, medial osteophytes and joint effusion were positive in all patients in MRI (the reference standard), therefore, in the statistical analysis we had no true negatives nor false positives for these parameters. Consequently, the specificity, NPVs and the $p$-values couldn't be calculated. Further larger studies are recommended, particularly, studies with larger patient numbers, including patients who are not already diagnosed as knee OA.

In conclusion ultrasound assessment of the knee joint is an accurate imaging method for detection of knee osteoarthritis parameters including femoral articular cartilage thinning, osteophytes, medial and lateral meniscal degeneration, joint effusion and Baker's cyst. Thus, knee ultrasound can be used as a complementary imaging technique to radiography, especially when MRI is not available, to assess tissue-specific structural OA degeneration not detected by conventional radiographs.

\section{References}

1- PODLIPSKÁ J., AROKOSKI J.P., GUERMAZI A., KAUKINEN P., KOSKI J.M., et al.: Comparison of Diagnostic Performance of Semi-Quantitative Knee Ultrasound and Knee Radiography with MRI: Oulu Knee Osteoarthritis Study Scientific Reports, 6: 22365, 2016.

2- AGRICOLA R., CARR A.J., GLYN-JONES S., PALMER A.J.R., PRICE A.J., et al.: Osteoarthritis The Lancet, 386 (9991): 376-87, 2015.

3- JAIN R. and JOHAR A.: To evaluate the role of high resolution ultrasonography in diagnosis of knee osteoarthritis International Journal of Orthopedics Sciences, 4 (1): 69-76, 2018.

4- HUNTER D.J., LINKLATER J.M. and OO W.M.: Imaging in knee Osteoarthritis Current Opinion in Rheumatology, 29 (1): 86-95, 2017.

5- OO W.M. and BO M.T.: Role of Ultrasonography in Knee Osteoarthritis. Journal of Clinical Rheumatology, 22 (6): 324-9, 2016.

6- SADEGHIAN H. and NIYA M.Z.: Ultrasound findings in knee osteoarthritis and rheumatoid arthritis compared to MRI Bali Medical Journal, 7 (2): 468-71, 2018.

7- FRIEDMAN L., FINLAY K. and JURRIAANS E.: Ultrasound of the knee Skeletal. Radiol., 30: 361-77, 2001.

8- KOSKI J.M., KAMEL A., WARIS P., WARIS V., TARKIAINEN I., et al.: Atlas-based knee osteophyte assessment with ultrasonography and radiography: Relationship to arthroscopic degeneration of articular cartilage. Scand J. Rheumatol., 45 (2): 158-64, 2016.

9- ABDEL RAZEK A.A. and EL-BASYOUNI S.R.: Ultrasound of knee osteoarthritis: Interobserver agreement and correlation with Western Ontario and McMaster Universities Osteoarthritis Clin. Rheumatol., 35: 997-1001, 2016. 


\section{دور التصوير بالموجات فوق الصوتية عالية الجودة المقال

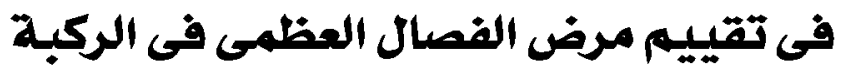

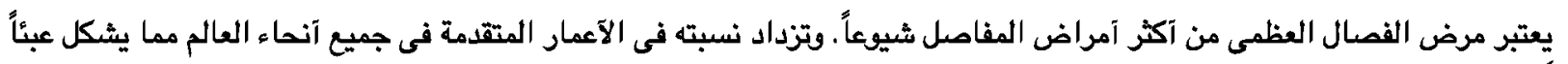

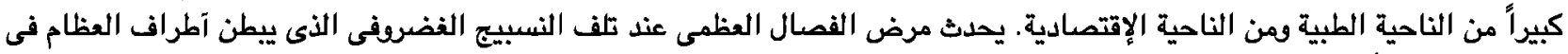
المفاصل تدريجياً، بالإضافة إلى تكوين النابتات العظمية، تاكل العظام والإرتشاح في العنى المفصل.

يقيم مرض الفصال العظمى فى مفصل الركبة مبدآياً عن طريق الآثـعة العادية وذلك عن طريق تقييم المسافة بين عظمتى المفصل والتفييرات

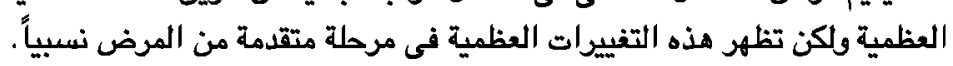

ويعتبر التصوير عن طريق الرنين المغناطيسى هو الوسيلة الآفضل حالياً لتشخيص التفييرات النسيجية فى مرض الفصال الفظمى وتحديد مدى إحتياج المريض لتغيير مفصل الركبة وآيضاً لمتابعة تطور المرضين.

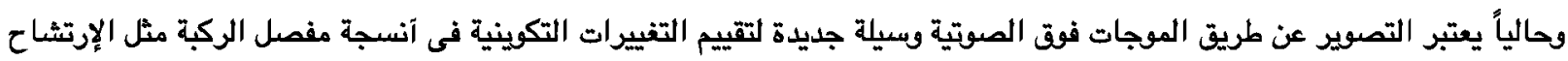
فى المفصل، الآكياس المائية، سمك النسيج الفضروفى الذى ييطن آطراف العظام، وتكوين النابتات العظمية.

لذا لـ ، تهدف هذه الدراسة إلى تقييم كفائة التصوير عن طريق الموجات فوق الصوتية فى تشخيص التغييرات التكوينية فى آنسجة مفصل

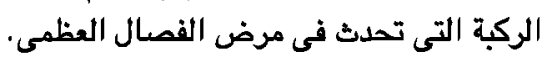

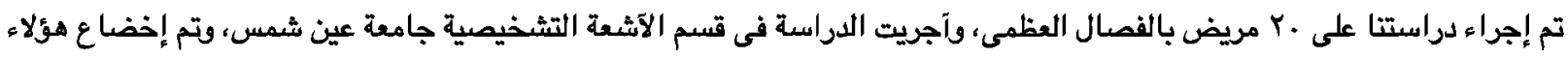

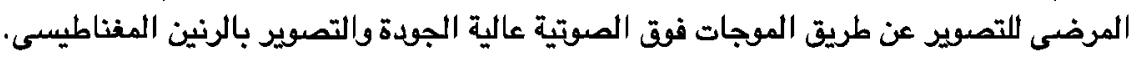

آظهرت نتائج الدراسة آن تصوير الركبة عن طريق الموجات فوق الصوتية عالية الجودة وسيلة فعالة ودقيقة للكشف عن التغييرات التكوينية

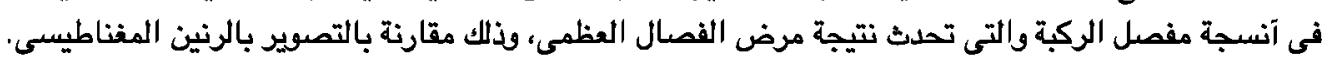
ولذلك نتصح بإستخدام تقنية التصوير بالموجات فوق الصوتية عالية الجودة لفصص مرضى الفصال العظمى بجانب التصوير بالآشعة

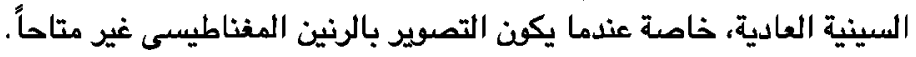

